УДК 582.998.1

\title{
БИОХИМИЧЕСКОЕ ИЗУЧЕНИЕ И ПЕРСПЕКТИВЫ ИСПОЛЬЗОВАНИЯ ПРЕДСТАВИТЕЛЕЙ РОДА DАНLIA CAV.
}

\author{
() С.Г. Денисова ${ }^{* 1}$, Л.Н. Миронова ${ }^{1}$, К.А. Пупыкина ${ }^{2}$
}

\author{
${ }^{1}$ Ботанический сад-институт Уфимского научного центра Российской \\ академии наук, ул. Менделеева, 195, корп. 3, Уфра, 450080 (Россия), \\ e-mail: svetik-7808@mail.ru \\ ${ }^{2}$ Башкирский государственный медицинский университет, ул. Ленина, 3, \\ Уфра, 450000 (Россия)
}

\begin{abstract}
Приведены результаты фитохимических исследований корнеклубней георгины Мерка (Dahlia merckii Lehm.) и 6 сортов георгины изменчивой (D. variabilis Desf.: «Color Spectacle», «Канзас», «Винни Пух», «Зной», «Лебедушка», «Черемушки»), а также объекта сравнения - топинамбура (Helianthus tuberosum L.). Определены качественные и количественные характеристики основных групп биологически активных веществ. Установлено, что содержание инулина составляет 11,9-66,5\%; дубильных веществ - 0,833-1,173\%; эфирных масел - 0,118-1,151\%; органических кислот - 0,190-0,213\%; свободных аминокислот - 6,14-11,37 мг\%; аскорбиновой кислоты - 0,200-0,240\%. Проведенные исследования элементного состава сырья георгины показали, что изученные таксоны являются перспективными источниками макро- и микроэлементов. Выявлена высокая способность корнеклубней георгины накапливать такие элементы, как кальций и марганец. Варьирование изученных показателей отражает разную биологическую ценность объектов исследования. В качестве альтернативного топинамбуру источника инулина предложены корнеклубни D. variabilis «Зной» и «Канзас», максимально накапливающие данный полисахарид, а также другие биологически активные вещества.

Ключевые слова: Dahlia merckii, Dahlia variabilis, Helianthus tuberosum, биологически активные вещества, фруктозаны, дубильные вещества, органические кислоты, аскорбиновая кислота, аминокислоты, эфирные масла, макрои микроэлементы.
\end{abstract}

\section{Введение}

Среди эндокринных заболеваний на долю сахарного диабета приходится примерно 70\%. Смертность от данного заболевания занимает третье место после сердечно-сосудистых и онкологических заболеваний.

В настоящее время фитотерапия является одним из распространенных методов профилактики и лечения инсулиннезависимого сахарного диабета, в связи с чем широкое применение получили инулинсодержащие субстанции [1].

Известно, что в США и странах Европы клубни георгин являются основным сырьем для получения инулина, обладающего широким спектром фармакологического действия [2]. В России в качестве инулин-

Денисова Светлана Галимулловна - научный сотрудник лаборатории интродукции и селекции цветочных растений, кандидат биологических наук, тел.: +7 (347) 228-13-55, e-mail: svetik-7808@mail.ru Миронова Людмила Николаевна - заведующая лабораторией интродукции и селекции цветочных растений, кандидат биологических наук, e-mail: flowers-ufa@yandex.ru

Пупыкина Кира Александровна - профессор кафедры фармакогнозии с курсом ботаники и основ фитотерапии, доктор фармацевтических наук, e-mail: pupykinak@ pochta.ru содержащего сырья используют клубни топинамбура, однако себестоимость такого продукта достаточно высока. Клубни топинамбура, в отличие от корнеклубней георгин, содержат карамелеобразующие фруктозаны и высокоактивные энзимы, способствующие осмолению полисахаридов, из-за чего возникает ряд проблем с технологией выделения и очистки инулина [1].

Эфирные масла, дубильные вещества, органические кислоты (в том числе аскорбиновая кисло-

\footnotetext{
* Автор, с которым следует вести переписку.
} 
та и аминокислоты), макро- и микроэлементы также имеют большое значение для организма человека, так как взаимодействуют с ферментной, эндокринной, иммунной и другими системами человеческого организма [3].

В связи с вышесказанным задачей наших исследований являлось экспериментальное обоснование применения клубней георгины в качестве альтернативного топинамбуру инулинсодержащего источника, а также химическое исследование на присутствие основных групп биологически активных веществ в зависимости от сортовых и видовых особенностей интродуцентов. В ранее опубликованных работах [4-7] уже сообщалось о некоторых результатах изучения химического состава корнеклубней четырех представителей рода Dahlia Cav. В настоящей статье приводится полный анализ итогов фитохимических исследований подземных органов семи таксонов георгины.

\section{Экспериментальная часть}

Для фитохимического исследования были взяты корнеклубни Dahlia merckii Lehm. и 6 сортов D. variabilis Desf. («Color Spectacle», «Канзас», «Винни Пух», «Зной», «Лебедушка», «Черемушки»; семейство Asteraceae Dumort.), выращенных на базе Ботанического сада-института Уфимского научного центра РАН. Эти образцы были выбраны в результате проведенных интродукционных исследований (20072012 гг.), на основе которых выявлено, что они хорошо переносят условия Башкирского Предуралья [8, 9]. За вегетационный период изученные таксоны образуют гнездо корнеклубней разной массы: 0,8 кг $(D$. merckii, D. variabilis «Лебедушка»), 1,0-1,5 кг (D. variabilis «Зной», «Канзас»), 2,2-2,7 кг (D. variabilis «Color Spectacle», «Черемушки»). Для сравнения использовали основной источник получения инулина в России - топинамбур (Helianthus tuberosum L., семейство Asteraceae Dumort.), который за период вегетации формировал массу подземных органов $0,6-0,9$ кг.

Для проведения анализа брали по 10 растений каждого сорта и вида в фазе плодоношения. Клубни выкапывали после первых осенних заморозков (конец сентября - начало октября), в результате которых надземная масса полностью погибала. Для количественного и качественного анализа корнеклубни высушивали до воздушно-сухого состояния, измельчали до размера частиц, проходящих сквозь сито с диаметром отверстий 1 мм, затем брали средний образец.

Определение качественных и количественных характеристик образцов проводилось на базе Башкирского государственного медицинского университета в аналитических пробах сырья по методикам Государственной фармокопеи XI издания [10] в трехкратной повторности. Для всех образцов находили показатель влажности сырья, который учитывали при расчетах количественного содержания биологически активных веществ. Качественное и количественное определение отдельных групп биологически активных веществ проводили в соответствии с методиками, описанными в «Государственной фармокопеи...» $[10,11]$. Количественное определение высокомолекулярных фруктозанов (инулин), низкомолекулярных фруктозанов (инулоиды) и фруктозы осуществлялось по методикам К.В. Белякова [12].

Определение аминокислот в исследуемых образцах проводили на аминокислотном анализаторе AАA-339 (ЧССР) в стандартных условиях, используемых для разделения белковых гидролизатов. Элементный состав определяли методом атомно-абсорбционной спектрометрии [13].

Статистическую обработку данных по биохимии сырья проводили в соответствии с требованиями «Государственной фармокопеи...» [10], с использованием критерия Стьюдента, с вычислением граничных значений доверительного интервала среднего результата и определением средней арифметической ошибки при различных значениях «n».

\section{Обсуждение результатов}

Для практического здравоохранения наибольший интерес представляют растения, содержащие ценные биологически активные вещества и являющиеся перспективными источниками их получения. В этом плане актуально изучение представителей семейства Asteraceae Dumort., а именно растений рода георгина (Dahlia Cav. или Georgina Wild).

Родина георгин - Мексика и Гватемала. Ацтеки использовали их клубни в питании, в приготовлении лечебных настоек [14]. Интерес к георгинам первоначально был вызван их способностью формировать крупные питательные корнеклубни. Поэтому и в Европу они попали в 1789 г. в качестве пищевых растений [15].

Биологически активные вещества в изучаемых образцах георгин представлены веществами разнообразной химической природы. В результате качественных реакций и хроматографического анализа в сырье нами обнаружены полисахариды, дубильные вещества, аскорбиновая кислота. 
Полисахариды. Как показали исследования $[16,17]$, в образцах корнеклубней георгины одновременно присутствуют фруктоза, инулин (высокомолекулярные фруктозаны) и инулоиды (низкомолекулярные фруктозаны).

При количественном определении каждой группы углеводов установлено, что максимальное накопление высокомолекулярных фруктозанов характерно для D. variabilis «Зной» $(66,55 \pm 1,99 \%)$ и «Канзас» $(59,96 \pm 1,68 \%)$, в H. tuberosum их содержание было в 1,2 раза меньше. В корнеклубнях D. variabilis «Color Spectacle», «Винни Пух» и D. merckii количество инулина было в 3,0-4,7 раза меньше, чем в H. tuberosum. По содержанию низкомолекулярных фруктозанов и фруктозы лидирующее положение занимает H. tuberosum (табл. 1).

Эфирные масла. В результате фитохимического анализа установлено, что эфирные масла входят в состав всех изучаемых таксонов георгины. Наиболее высоким содержанием отличаются корнеклубни D. variabilis «Канзас» и «Черемушки» (1,151 и 1,143\% соответственно). В клубнях H. tuberosum обнаружены только следы эфирного масла (табл. 2).

Дубильные вещества. При количественном определении дубильных веществ было выявлено, что максимальным содержанием данной группы веществ характеризуются корнеклубни D. merckii $(1,173 \pm 0,036 \%)$ и D. variabilis «Канзас» $(1,072 \pm 0,044 \%)$ (табл. 2$)$.

Органические кислоты. При определении содержания органических кислот в исследуемом растительном сырье отмечали более высокое их накопление в топинамбуре $(0,463 \pm 0,020 \%)$, по сравнению с сор-

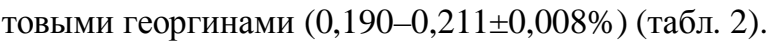

Результаты оценки содержания аскорбиновой кислоты во всех исследуемых объектах показали, что в сырье георгины количество витамина С (от 0,200 у D. variabilis «Лебедушка» до 0,242\% у D. variabilis

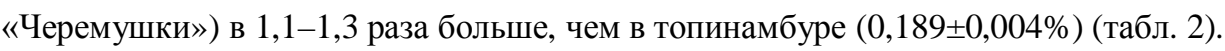

Проведено количественное определение аминокислот в исследуемых объектах. Установлено присутствие 14 аминокислот, 7 из которых являются незаменимыми (табл. 3, 4). По суммарному содержанию аминокислот лидирующее положение занимают анализируемые сорта георгины, которые значительно превосходят D. merckii и объект сравнения - H. tuberosum.

Таблица 1. Показатели содержания фруктозанов в сырье Dahlia и Helianthus

\begin{tabular}{l|c|c|c}
\hline \multirow{2}{*}{ Исследуемый объект } & \multicolumn{3}{|c}{ Содержание фруктозанов, \% (х $\left.\pm \mathrm{E}_{\alpha}\right)$} \\
\cline { 2 - 4 } & Инулин & Инулоиды & Фруктоза \\
\hline H. tuberosum & $56,06 \pm 1,35$ & $13,78 \pm 0,51$ & $29,11 \pm 0,82$ \\
D. merckii L. & $16,58 \pm 0,49$ & $9,52 \pm 0,34$ & $5,25 \pm 0,25$ \\
\hline \multicolumn{3}{|c}{ D. variabilis: } \\
\hline «Винни Пух» & $11,81 \pm 0,33$ & $1,75 \pm 0,03$ & $4,53 \pm 0,13$ \\
«ной» & $66,55 \pm 1,99$ & $2,04 \pm 0,01$ & $5,75 \pm 0,17$ \\
«Канзас» & $59,96 \pm 1,68$ & $6,31 \pm 0,18$ & $9,11 \pm 0,26$ \\
«Соlor Spectacle» & $18,67 \pm 0,49$ & $12,35 \pm 0,31$ & $9,44 \pm 0,27$ \\
«Лебедушка» & $49,41 \pm 1,48$ & $4,29 \pm 0,09$ & $3,51 \pm 0,08$ \\
«Черемушки» & $50,27 \pm 1,42$ & $7,20 \pm 0,22$ & $10,33 \pm 0,26$ \\
\hline
\end{tabular}

Таблица 2. Содержание эфирных масел, дубильных веществ, органических и аскорбиновой кислот в сырье Dahlia и Helianthus

\begin{tabular}{|c|c|c|c|c|}
\hline \multirow[t]{2}{*}{ Исследуемый объект } & \multicolumn{4}{|c|}{ Содержание, \% $\left(x \pm E_{\alpha}\right)$} \\
\hline & эфирных масел & дубильных веществ & $\begin{array}{c}\text { органических кис- } \\
\text { лот }\end{array}$ & $\begin{array}{c}\text { аскорбиновой кисло- } \\
\text { ты }\end{array}$ \\
\hline $\begin{array}{l}\text { H. tuberosum } \\
\text { D. merckii }\end{array}$ & $\begin{array}{c}- \\
0,221 \pm 0,005\end{array}$ & $\begin{array}{l}0,918 \pm 0,031 \\
1,173 \pm 0,036\end{array}$ & $\begin{array}{l}0,463 \pm 0,020 \\
0,208 \pm 0,009\end{array}$ & $\begin{array}{l}0,189 \pm 0,004 \\
0,210 \pm 0,005\end{array}$ \\
\hline \multicolumn{5}{|c|}{ D. variabilis: } \\
\hline $\begin{array}{l}\text { «Винни Пух» } \\
\text { «Зной» } \\
\text { «Канзас» } \\
\text { «Color Spectacle» } \\
\text { «Лебедушка» } \\
\text { «Черемушки» }\end{array}$ & $\begin{array}{l}0,471 \pm 0,014 \\
0,639 \pm 0,019 \\
1,151 \pm 0,035 \\
0,580 \pm 0,026 \\
0,118 \pm 0,020 \\
1,143 \pm 0,032\end{array}$ & $\begin{array}{l}0,849 \pm 0,025 \\
0,897 \pm 0,027 \\
1,072 \pm 0,044 \\
0,944 \pm 0,028 \\
0,868 \pm 0,017 \\
0,833 \pm 0,022\end{array}$ & $\begin{array}{l}0,205 \pm 0,004 \\
0,197 \pm 0,004 \\
0,211 \pm 0,010 \\
0,209 \pm 0,010 \\
0,213 \pm 0,006 \\
0,190 \pm 0,008\end{array}$ & $\begin{array}{l}0,234 \pm 0,008 \\
0,228 \pm 0,006 \\
0,216 \pm 0,007 \\
0,240 \pm 0,008 \\
0,200 \pm 0,004 \\
0,242 \pm 0,008\end{array}$ \\
\hline
\end{tabular}


Таблица 3. Содержание незаменимых аминокислот в сырье Dahlia и Helianthus

\begin{tabular}{|c|c|c|c|c|c|c|c|c|c|}
\hline \multirow{3}{*}{$\begin{array}{c}\text { Объект } \\
\text { исследования }\end{array}$} & \multicolumn{9}{|c|}{ Содержание аминокислот, мг\% } \\
\hline & \multirow{2}{*}{ лизин } & \multirow{2}{*}{ метионин } & \multirow{2}{*}{ треонин } & \multirow{2}{*}{ валин } & \multirow{2}{*}{$\begin{array}{c}\text { изолей- } \\
\text { цин }\end{array}$} & \multirow{2}{*}{ лейцин } & \multirow{2}{*}{$\begin{array}{l}\text { фенил- } \\
\text { аланин }\end{array}$} & \multicolumn{2}{|c|}{$\begin{array}{l}\text { Суммарное } \\
\text { содержание }\end{array}$} \\
\hline & & & & & & & & $\begin{array}{l}\text { незаме- } \\
\text { нимых }\end{array}$ & общее \\
\hline H. tuberosum & 1,21 & 0,21 & 0,08 & 2,5 & 0,19 & 0,48 & 0,14 & 4,81 & 6,85 \\
\hline D. merckii & 1,06 & 0,10 & 0,10 & 2,11 & 0,18 & 0,34 & 0,15 & 4,04 & 6,66 \\
\hline \multicolumn{10}{|c|}{ D. variabilis: } \\
\hline «Винни Пух» & 2,30 & 0,44 & 0,24 & 2,60 & 0,30 & 0,90 & 0,24 & 7,02 & 10,29 \\
\hline «Зной» & 1,76 & 0,29 & 0,07 & 3,24 & 0,15 & 0,46 & 0,03 & 6,00 & 9,71 \\
\hline «Канзас» & 2,36 & 0,47 & 0,29 & 3,39 & 0,01 & 0,84 & 0,2 & 7,56 & 11,37 \\
\hline «Color Spectacle» & 1,75 & 0,31 & 0,12 & 2,10 & 0,38 & 0,71 & 0,11 & 5,48 & 7,87 \\
\hline «Лебедушка» & 0,93 & 0,02 & 0,21 & 0,89 & 0,72 & 0,33 & 0,06 & 3,16 & 6,14 \\
\hline «Черемушки» & 2,08 & 0,40 & 0,19 & 3,06 & 0,06 & 0,74 & 0,10 & 6,63 & 9,96 \\
\hline
\end{tabular}

Таблица 4. Содержание заменимых аминокислот в сырье Dahlia и Helianthus

\begin{tabular}{|c|c|c|c|c|c|c|c|c|c|}
\hline \multirow{3}{*}{$\begin{array}{c}\text { Объект } \\
\text { исследования }\end{array}$} & \multicolumn{9}{|c|}{ Содержание аминокислот, мг\% } \\
\hline & \multirow{2}{*}{ цистеин } & \multirow{2}{*}{ гистидин } & \multirow{2}{*}{ аргинин } & \multirow{2}{*}{ серин } & \multirow{2}{*}{ пролин } & \multirow{2}{*}{ глицин } & \multirow{2}{*}{ тирозин } & \multicolumn{2}{|c|}{$\begin{array}{l}\text { Суммарное } \\
\text { содержание }\end{array}$} \\
\hline & & & & & & & & $\begin{array}{c}\text { замени- } \\
\text { мых }\end{array}$ & общее \\
\hline H. tuberosum & 0,94 & 0,34 & 0,20 & 0,02 & 0,13 & 0,29 & 0,12 & 2,04 & 6,85 \\
\hline D. merckii & 0,96 & 0,25 & 0,41 & 0,30 & 0,07 & 0,52 & 0,11 & 2,62 & 6,66 \\
\hline \multicolumn{10}{|c|}{ D. variabilis: } \\
\hline «Винни Пух» & 1,07 & 0,61 & 0,02 & 0,05 & 1,28 & 0,25 & 0,01 & 3,29 & 10,31 \\
\hline «Зной» & 1,07 & 0,41 & 0,28 & 0,15 & 1,30 & 0,35 & 0,15 & 3,71 & 9,71 \\
\hline «Канзас» & 1,14 & 0,63 & 0,03 & 0,05 & 1,69 & 0,18 & 0,09 & 3,81 & 11,37 \\
\hline «Color Spectacle» & 0,76 & 0,48 & 0,04 & 0,18 & 0,34 & 0,45 & 0,14 & 2,39 & 7,87 \\
\hline «Лебедушка» & 0,74 & 0,18 & 0,43 & 0,52 & 0,45 & 0,65 & 0,01 & 2,98 & 6,14 \\
\hline «Черемушки» & 1,11 & 0,54 & 0,10 & 0,07 & 1,18 & 0,25 & 0,08 & 3,33 & 9,96 \\
\hline
\end{tabular}

Сумма незаменимых аминокислот составляет от 3,16 (D. variabilis «Лебедушка») до 7,56 мг\% (D. variabilis «Канзас»), сумма всех аминокислот - 6,14-11,37 мг\%, что является достаточно высоким показателем для растений и отражает биологическую ценность объектов исследования.

Элементный состав. На основании проведенных исследований минерального состава корнеклубней георгин установлено наличие девяти элементов, из которых четыре являются макроэлементами, пять - микроэлементами. Причем качественный состав элементов, содержащийся в сырье разных видов георгины и в топинамбуре, был практически идентичен, в то время как их количество существенно различалось. Так, больше всего натрия (0,24\%), кальция (3,35\%), железа (2465,31 мг/кг), меди (24,68 мг/кг), марганца (1294,90 мг/кг), йода (0,14 мг/кг) отмечено в образцах сырья D. variabilis «Канзас»; калия $(1,65 \%)-$ D. variabilis «Винни Пух»; фосфора $(0,48 \%)$ - H. tuberosum; цинка (153,55 мг/кг) - D. variabilis «Color Spectacle» (табл. 5). Следует отметить, что во всех исследуемых образцах георгины в преобладающей концентрации содержатся кальций и калий, далее в порядке убывания следуют фосфор, натрий, железо, марганец, цинк, медь, йод. В топинамбуре же лидирующее положение занимают калий и фосфор, затем следуют натрий, кальций, желе3о, цинк, марганец, медь, йод, что отражает родовые особенности элементного состава изученных объектов. Выявлена высокая способность корнеклубней георгины накапливать такие элементы, как кальций и марганец. Их содержание в 13,4-55,8 раза превосходило показатели сырья из клубней топинамбура.

Полученные нами результаты подтверждаются данными сотрудников Пятигорской государственной фармацевтической академии [1]. Так, Н.А. Ананьиной [1] установлено, что содержание инулина в клубнях 5 сортов Dahlia linearis Sherff. составляет 24,03-34,38\%, свободных органических кислот - 0,2 $\pm 0,002 \%$, ду-

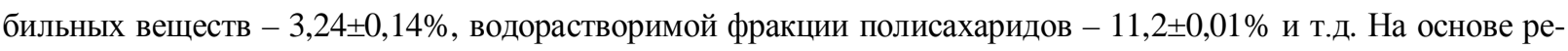
зультатов фитохимического анализа автор рекомендует в качестве альтернативного источника инулина клубни георгины, собранные в фазу плодоношения на втором году жизни растений.

Таким образом, результаты изучения фитохимического состава корнеклубней сортов D. variabilis Desf. «Канзас» и «Зной» позволяют рекомендовать их для дальнейших углубленных исследований. 
Таблица 5. Элементный состав сырья Dahlia и Helianthus

\begin{tabular}{|c|c|c|c|c|c|c|c|c|c|}
\hline \multirow[t]{2}{*}{ Виды и сорта } & \multicolumn{4}{|c|}{ Макроэлементы, \% } & \multicolumn{5}{|c|}{ Микроэлементы, мг/кг } \\
\hline & $\bar{K}$ & $\mathrm{Na}$ & $\mathrm{Ca}$ & $\mathrm{P}$ & $\mathrm{Zn}$ & $\mathrm{Fe}$ & $\mathrm{Cu}$ & $\mathrm{Mn}$ & $\mathrm{J}$ \\
\hline H. tuberosum & 0,51 & 0,07 & 0,06 & 0,48 & 60,03 & 1090,96 & 5,84 & 30,84 & 0,08 \\
\hline D. merckii & 1,04 & 0,01 & 2,32 & 0,45 & 90,29 & 1087,78 & 7,67 & 804,25 & 0,01 \\
\hline \multicolumn{10}{|c|}{ D. variabilis: } \\
\hline «Винни Пух» & 1,65 & 0,18 & 3,07 & 0,38 & 140,31 & 1867,84 & 19,45 & 1035,50 & 0,10 \\
\hline «Зной» & 1,52 & 0,17 & 3,27 & 0,47 & 141,83 & 2072,87 & 21,04 & 1241,70 & 0,09 \\
\hline «Канзас» & 1,54 & 0,24 & 3,35 & 0,45 & 150,14 & 2465,31 & 24,68 & 1294,90 & 0,14 \\
\hline «Color Spectacle» & 1,53 & 0,04 & 2,50 & 0,25 & 153,55 & 1505,86 & 14,49 & 891,11 & 0,02 \\
\hline «Лебедушка» & 1,25 & 0,09 & 2,18 & 0,22 & 82,68 & 1650,60 & 0,53 & 414,47 & 0,07 \\
\hline «Черемушки» & 1,29 & 0,18 & 3,05 & 0,41 & 137,23 & 2163,30 & 20,37 & 1167,90 & 0,11 \\
\hline
\end{tabular}

\section{Bblвodbl}

Проведены фитохимические исследования корнеклубней георгины Мерка (Dahlia merckii Lehm.) и 6 сортов георгины изменчивой (D. variabilis Desf.: «Color Spectacle», «Канзас», «Винни Пух», «Зной», «Лебедушка», «Черемушки»), а также объекта сравнения - топинамбура (Helianthus tuberosum L.).

Определены качественные и количественные характеристики основных групп биологически активных веществ. Установлено, что содержание инулина составляет 11,9-66,5\%; дубильных веществ - 0,833$1,173 \%$; эфирных масел - 0,118-1,151\%; органических кислот - 0,190-0,213\%; свободных аминокислот 6,14-11,37 мг\%; аскорбиновой кислоты - 0,200-0,240\%. Проведенные исследования элементного состава сырья георгины показали, что изученные виды и сорта являются перспективными источниками макрои микроэлементов. Выявлена высокая способность корнеклубней георгины накапливать такие элементы, как кальций и марганец. Их содержание в 13,4-55,8 раза превосходило показатели сырья из клубней топинамбура. Варьирование изученных показателей отражает разную биологическую ценность объектов исследования. В качестве альтернативного топинамбуру источника инулина предложены корнеклубни D. variabilis «Зной» и «Канзас», в большом количестве накапливающие данный полисахарид и другие биологически активные вещества.

\section{Список литературь}

1. Ананьина Н.А. Использование клубней георгины простой как альтернативного источника получения инулина : автореф. дисс. ... канд. фарм. наук. Пятигорск, 2011. 22 с.

2. Nilsson U., BjOrck I. Availability of cereal fructans and inulin in the rat intestinal tract // Carbohydrate and Fiber. New York, 1988. Pp. 1482-1486.

3. Гринкевич Н.И., Сафронович Л.Н. Химический анализ лекарственных растений. М., 1983. 176 с.

4. Денисова С.Г., Пупыкина К.А., Миронова Л.Н. Изучение полисахаридного комплекса корнеклубней георгин (Dahlia Cav.) // Медицинский вестник Башкортостана. 2012. Т. 7, №5. С. 36-37.

5. Денисова С.Г., Пупыкина К.А., Миронова Л.Н., Файзуллина Р.Р. Особенности накопления биологически активных веществ в корнеклубнях георгин // Традиционная медицина. 2012. №5. С. 213-215.

6. Миронова Л.Н., Пупыкина К.А., Денисова С.Г., Файзуллина Р.Р. Результаты сравнительного изучения химического состава подземных органов георгины и топинамбура // Вестник Оренбургского государственного университета. 2009. №6. С. 234-236.

7. Пупыкина К.А., Файзуллина Р.Р., Миронова Л.Н., Денисова С.Г. Анализ накопления и локализации эфирных масел в корнеклубнях георгин (Dahlia Cav.) различных сортов // Вестник Оренбургского государственного университета. 2009. №6. С. 296-298.

8. Миронова Л.Н., Воронцова А.А., Шипаева Г.В. Итоги интродукции и селекции декоративных травянистых растений в Республике Башкортостан. М., 2006. Ч. 1. 211 с.

9. Каталог растений Ботанического сада-института Уфимского научного центра РАН / под ред. В.П. Путенихина. Уфа, 2005. 224 с.

10. Государственная фармакопея СССР. 11-е издание: Вып. 1. Общие методы анализа. М., 1987. 336 с.

11. Государственная фармакопея СССР. 11-е издание: Вып. 2. Общие методы анализа. Лекарственное растительное сырье. М., 1990. 400 с.

12. Беляков К.В. Методологические подходы к определению биологически активных веществ в лекарственном растительном сырье спектрофотометрическим методом. М., 2004. 188 с.

13. Брицке М.Э. Атомно-абсорбционный спектрохимический анализ М., 1982. 224 с.

14. Заливский И.Л. Георгины. М., 1954. 144 с.

15. Киселев Г.Е. Цветоводство. М., 1952. 975 с. 
16. Денисова С.Г., Пупыкина К.А., Миронова Л.Н., Файзуллина Р.Р. Изучение корнеклубней георгин как перспективного инулинсодержащего сырья // Башкирский химический журнал. 2010. Т. 1, №2. С. 121-122.

17. Денисова С.Г., Пупыкина К.А., Миронова Л.Н., Файзуллина Р.Р. Полисахариды в составе георгин // Научные ведомости Белгородского государственного университета. Серия Естественные науки. 2011. №3 (98), вып. 14/1. С. 355-359.

18. Пупыкина К.А., Миронова Л.Н., Денисова С.Г., Файзуллина Р.Р. Изучение аминокислотного и элементного состава подземных органов некоторых представителей рода Dahlia Cav. // Вестник Воронежского государственного университета. Серия География. Геоэкология. 2011. №2. С. 84-86.

Поступило в редакциюю 22 января 2015 г.

После переработки 20 марта 2015 г. 
Denisova S.G. ${ }^{{ }^{*}}$, Mironova L.N. ${ }^{l}$, Pupykina K.A. ${ }^{2}$ THE BIOCHEMICAL STUDY AND PERSPECTIVE OF USING REPRESENTATIVES OF THE GENUS DAHLIA CAV.

${ }^{1}$ Ufa Botanical Garden, Ufa Scientific Center of the RAS, Mendeleeva st., 195-3, Ufa, 450080 (Russia),

e-mail: svetik-7808@mail.ru

${ }^{2}$ Bashkir State Medical University, Lenina st., 3, Ufa, 450000 (Russia)

The results of phytochemical research of root-tubers Merck dahlia (Dahlia merckii Lehm.) And 6 varieties of dahlias variable (D. variabilis Desf .: «Color Spectacle», «Kansas», «Winnie the Pooh», «Znoy», «Lebedushka» «Cheremushki»), as well as the object of comparison - Jerusalem artichoke (Helianthus tuberosum L.) are given in this paper. Defined qualitative and quantitative characteristics of main groups of biologically active substances. The content of inulin is $11,9-66,5 \%$; tannins 0,833-1,173\%; essential oils - 0,118-1,151\%; organic acids $-0,190-0,213 \%$; free amino acids $-6,14-11,37 \mathrm{mg} \%$; ascorbic acid $-0,200-0,240 \%$. Studies of the elemental composition of raw materials of dahlias showed that the studied taxa are promising sources of macro and micronutrients. Identified a high potential to accumulate in root-tubers an elements such as calcium and manganese. Varying of the studied parameters reflect the different biological value of the objects of research. As an alternative source of Jerusalem artichoke inulin proposed the root-tubers of D. variabilis «Znoy» and «Kansas», which can accumulate the maximum of this polysaccharide as well as other biologically active substances.

Keywords: Dahlia merckii, Dahlia variabilis, Helianthus tuberosum, Biologically active substances, fructosans, tannins, organic acids, ascorbic acid, amino acids, essential oils, macro and microelements.

\section{References}

1. Anan'ina N.A. Ispol'zovanie klubnei georginy prostoi kak al'ternativnogo istochnika polucheniia inulina : avtoref. dis. ... kand. farm. nauk. [Using a simple dahlia tubers as an alternative source of inulin: dissertation of the candidate of pharmaceutical sciences]. Pyatigorsk, 2011, 22 p. (in Russ.).

2. Nilsson U., BjOrck I. Carbohydrate and Fiber, New York, 1988, pp. 1482-1486.

3. Grinkevich N.I., Safronovich L.N. Khimicheskii analiz lekarstvennykh rastenii. [Chemical analysis of medicinal plants]. Moscow, 1983, 176 p. (in Russ.).

4. Denisova S.G., Pupykina K.A., Mironova L.N. Meditsinskii vestnik Bashkortostana, 2012, vol. 7, no. 5, pp. 36-37. (in Russ.).

5. Denisova S.G., Pupykina K.A., Mironova L.N., Faizullina R.R. Traditsionnaia meditsina, 2012, no. 5, pp. $213-215$. (in Russ.).

6. Mironova L.N., Pupykina K.A., Denisova S.G., Faizullina R.R. Vestnik Orenburgskogo gosudarstvennogo universiteta, 2009, no. 6, pp. 234-236. (in Russ.).

7. Pupykina K.A., Faizullina R.R., Mironova L.N., Denisova S.G. Vestnik Orenburgskogo gosudarstvennogo universiteta, 2009, no. 6, pp. 296-298. (in Russ.).

8. Mironova L.N., Vorontsova A.A., Shipaeva G.V. Itogi introduktsii i selektsii dekorativnykh travianistykh rastenii $v$ Respublike Bashkortostan. [The results of the introduction and breeding of ornamental grasses in the Republic of Bashkortostan]. Moscow, 2006, part. 1, 211 p. (in Russ.).

9. Katalog rastenii Botanicheskogo sada-instituta Ufimskogo nauchnogo tsentra RAN. [Catalogue of plants Botanical Garden-Institute, Ufa Scientific Center, RAS]. Ed. V.P. Putenikhin. Ufa, 2005, 224 p. (in Russ.).

10. Gosudarstvennaia farmakopeia SSSR. Vyp. 1. Obshchie metody analiza. [The State pharmacopoeia of the USSR. Issue 1: General methods of analysis]. Moscow, 11 ed., 1987, 336 p. (in Russ.).

11. Gosudarstvennaia farmakopeia SSSR. Vyp. 2. Obshchie metody analiza. Lekarstvennoe rastitel'noe syr'e. [State Pharmacopoeia of the USSR. Issue 2. General methods of analysis. Medicinal herbs]. Moscow, 11 ed., 1990, 400 p. (in Russ.).

12. Beliakov K.V. Metodologicheskie podkhody $k$ opredeleniiu biologicheski aktivnykh veshchestv v lekarstvennom rastitel'nom syr'e spektrofotometricheskim metodom. [Methodological approaches to the determination of biologically active substances in medicinal herbs by spectrophotometry]. Moscow, 2004, 188 p. (in Russ.).

13. Britske M.E. Atomno-absorbtsionnyi spektrokhimicheskii analiz. [Atomic absorption spectrochemical analysis]. Moscow, 1982, 224 p. (in Russ.).

14. Zalivskii I.L. Georginy. [Dahlias]. Moscow, 1954, 144 p. (in Russ.).

15. Kiselev G.E. Tsvetovodstvo. [Floriculture]. Moscow, 1952, 975 p. (in Russ.).

16. Denisova S.G., Pupykina K.A., Mironova L.N., Faizullina R.R. Bashkirskii khimicheskii zhurnal, 2010, vol. 1, no. 2, pp. 121-122. (in Russ.).

17. Denisova S.G., Pupykina K.A., Mironova L.N., Faizullina R.R. Nauchnye vedomosti Belgorodskogo gosudarstvennogo universiteta. Seriia Estestvennye nauki, 2011, no. 3(98), issue 14/1, pp. 355-359. (in Russ.).

18. Pupykina K.A., Mironova L.N., Denisova S.G., Faizullina R.R. Vestnik Voronezhskogo gosudarstvennogo universiteta. Seriia Geografiia. Geoekologiia, 2011, no. 2, pp. 84-86. (in Russ.).

Received January 22, 2015

Revised March 20, 2015

\footnotetext{
* Corresponding author.
} 
